\title{
Development of a Deterioration Diagnosis Device for Arresters on Shinkansen Feeding Circuits
}

\author{
Hiroki TANAKA \\ Assistant Senior Researcher, Assistant Senior Researcher, \\ Hiroaki MORIMOTO \\ Power Supply Systems Laboratory, Power Supply Technology Division \\ Tsurugi YOSHII \\ Researcher, \\ Power Supply Systems Laboratory, Power Supply Technology Division \\ Tetsuo UZUKA \\ Laboratory Head
}

Kohji AJIKI

Sankosha Co., Ltd.

Two methods currently exist to evaluate degradations in arresters in Shinkansen substations. One method uses a surge current counter device to count the number of strokes of lightning. However, surge current counter devices sometimes pick up small switching surge of changeover switches, which are not deterioration to the arrester. The other method is to measure normal leakage current of arrester. This method though is potentially unreliable because the leakage current is strongly affected by the feeding voltage harmonics. A deterioration diagnosis device was thus designed with functions to suppress unwanted small surge current counts and provide accurate measurements of the leakage current in the target arrester. This paper describes various field measurement results, the principle underlying the developed deterioration diagnosis device and a new method for extracting the resistive current in the arrester from the overall measured leakage current.

Keywords: AC electric railway, arrester, degradation, leakage current

\section{Introduction}

Arresters used on Shinkansen lines have the role of absorbing train switching surges, and lightning surges from outside lines to protect the insulation of the device. At present there are two methods to prevent damage to the arrester. One is to manage the leakage current value, and the other is to manage the number of counts registered by a surge current counter device installed in the ground circuit.

Both methods however have drawbacks. There are cases where counters record very small discharge current caused by surge voltages from the change-over switch which do not cause deterioration to the arrester [1]. Furthermore, since it is difficult to accurately measure the leakage current with a general-purpose clamp meter, a more suitable approach is needed to manage deterioration prevention.

Consequently, the operation of the counter was improved, and a deterioration diagnosis device was developed which can accurately measure the arrester's leakage current waveform. In addition, the surge current and arrester leakage current were measured using the device temporarily installed at a Shinkansen substation. This confirmed that the device functions well, and that it was possible to detect the resistive current, required for diagnosis of the arrester deterioration, based on the leakage current waveform.

\section{Equivalent circuit and installation position of the arrester}

Figure 1 shows the installation position of the arrester. Figure 2 shows the equivalent circuit of the arrester. The arrester is represented by a parallel circuit of $C$ (capacitance to ground) and $R$ (zinc oxide element resistance). $R$ has a characteristic whereby the value of resistance varies according not only to the applied voltage but also deterioration of the element. Furthermore, current that can be

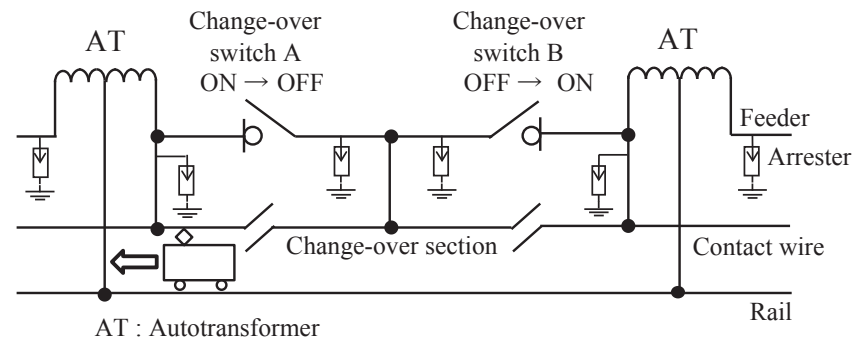

Fig. 1 Installation position of the arrester (sectioning post)

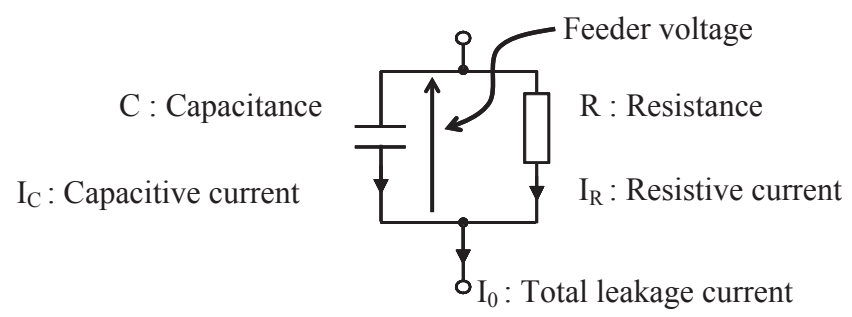

Fig. 2 Equivalent reproduction of the arrester circuit 
measured in the ground circuit of the arrester is the total leakage current $I_{0}$, which is the sum of $I_{\mathrm{R}}$ (resistive current) and $I_{\mathrm{C}}$ (capacitive current).

\section{Current of arrester}

As shown in Fig.1, the arrester is installed between the ground and the high voltage circuit. When it is invaded by a lightning surge voltage, it prevents the breakdown of the device by discharging lightning surge. However, with arresters on Shinkansen line feeding circuits sometimes discharge current occurs due to a surge voltage caused by the operation of change-over switches [2].

\subsection{Total leakage current}

Figure 3 shows the waveform of the total leakage current $I_{0}$ that was measured in the Shinkansen substation. The phase of the total leakage current $I_{0}$ is approximately 90 degrees ahead of the feeding voltage waveform. Therefore, Capacitive current $I_{\mathrm{C}}$ is dominant in the total leakage current $I_{0}$. In addition, Capacitive current $I_{\mathrm{C}}$ often contains a number of harmonics, which greatly affect the measured value of total leakage current $I_{0}$.

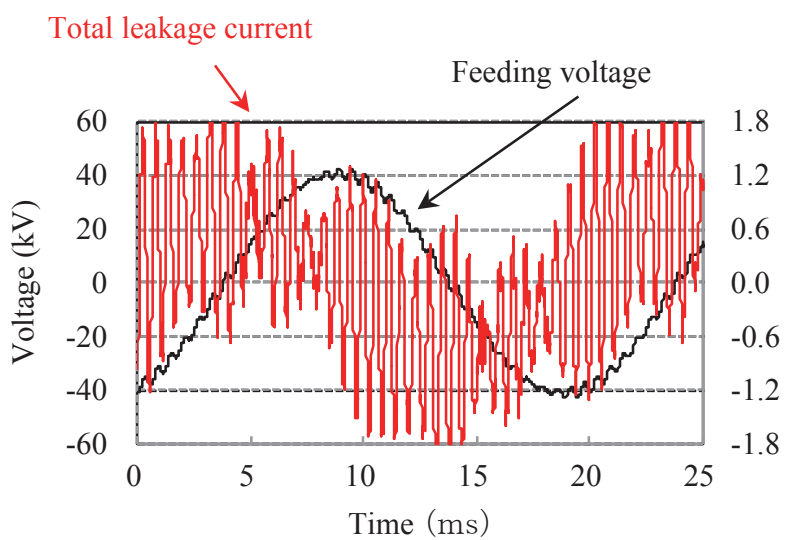

Fig. 3 Total leakage current waveform of the arrester in the Shinkansen substation

\subsection{Discharge current due to surge voltage caused by change-over switching}

The following is an example of a case where the discharge current due to surge voltage caused by a changeover switch flows through the arrester for the feeding circuit. Feeding system of shinkansen adopts a different phase feeding for direction. As shown in Fig.1, Shinkansen installed paired change-over switches into neutral sections to reduce the coasting time to only $0.3 \mathrm{~s}$ in front of each substation and sectioning post to change electric phase. Pair of vacuum circuit breakers were introduced as changeover switches. Surge voltage is generated by the operation of a change-over switch. Surge voltages have two patterns: one which occurs when the train enters a section, and the other when the train leaves a section.

Figure 4(a) shows the surge voltage waveform caused by change-over switching after a train has passed the section. Figure 4(b) shows a typical example of the mea-

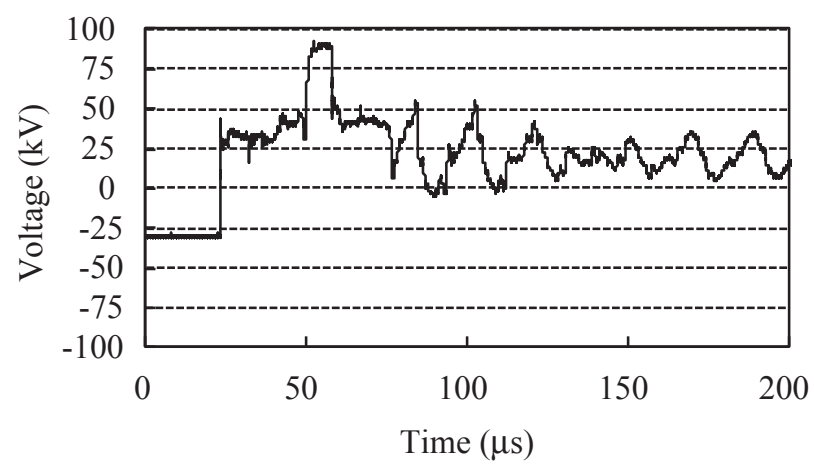

(a) Surge voltage

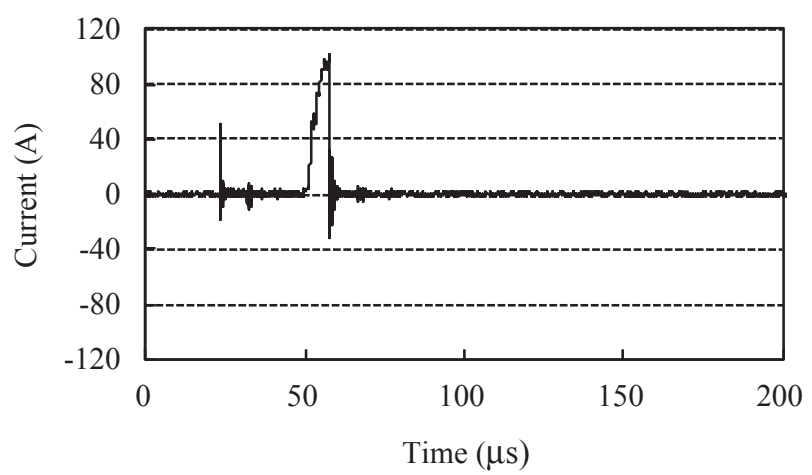

(b) Arrester current

Fig. 4 Total leakage current waveform of arrester at the Shinkansen substation

sured waveform through the arrester when the changeover switch has returned to standby. A discharge current of 95A flows into the arrester in Fig.4(b). This confirmed the discharge phenomenon which occurs by change-over switching. The surge voltage during change-over switching is known from measured results to be approximately $40-100 \mathrm{kV}[2,3]$.

\section{Conventional arrester deterioration diagnosis}

The following is a conventional technique for the diagnosis arrester degradation through applied voltage.

\subsection{Method for detecting the total leakage current}

When the arrester element is degraded, zinc oxide element resistance $R$ is reduced, and the resistance current $I_{\mathrm{R}}$ increases. As a result, the total leakage current $I_{0}$, which is the combined value of current $I_{\mathrm{C}}$ and current $I_{\mathrm{R}}$, increases. This is a method for determining the quality of the insulating state of the element based on the value of the total leakage current $I_{0}$.

\subsection{Method for detecting the resistive current by vector operation}

This method is used where the phase of the voltage vector $\mathbf{V}$ and the resistive current vector $\boldsymbol{I}_{\mathrm{R}}$ correspond. First, the phase difference $\Phi$ between $\mathbf{V}$ and the total leak- 
age current vector $\boldsymbol{I}_{\mathbf{0}}$ are determined. Second, this method is also used to diagnose the resistive current $I_{R}$ from cosine components $\left(\boldsymbol{I}_{0} \cos \Phi\right)$ of $\boldsymbol{I}_{0}$. This method is more reliable than other approaches to detect total leakage current for separating out the resistive current. However, filters, etc. must be used to remove the influence of harmonics and a complicated arithmetic circuit is needed.

\subsection{The number of times the counter operates}

Arresters are installed between the high voltage circuit and the ground in Shinkansen substations. This circuit has a counter which operates each time a lightning surge voltage makes an arrester discharge. There are cases, however, at the substation and sectioning posts along a Shinkansen line where the counter may be triggered to operate only by small current discharges. Small current discharges of about $100 \mathrm{~A}$ are generated by the switching surge which always occurs when a train passes [2]. It is difficult to distinguish whether a counter has been triggered by a switching surge or a lightning surge. It is therefore difficult to use the number of times of a counter is operated as a means to manage deterioration.

\section{Traditional diagnostic techniques of arrester deg- radation}

Figure 5 shows the counter circuit of an existing arrester. When the discharging current of the arrester flows through the circuit, it is charged to the capacitor. If the charging voltage reaches the starting potential of a zinc oxide element (varistor) the discharge current will flow into the varistor maintaining the charge voltage down to the varistor's limit voltage. The electric charge from the capacitor flows into the electromagnetic counter through a resistance, and operates the counter. When the lightning impulse current of the tail wave is about $10 \mu \mathrm{s}$, the minimum operating current of the counter is about 40-50 A.

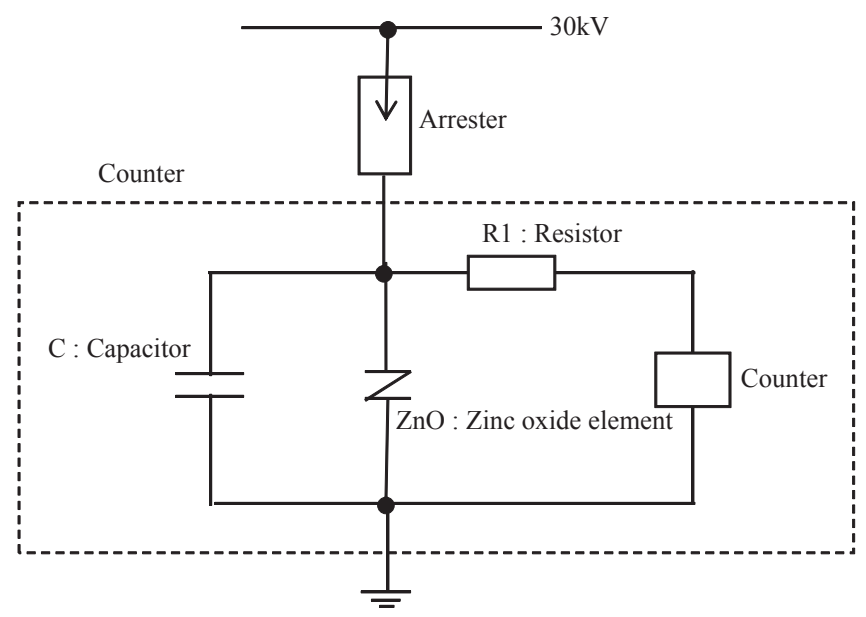

Fig. 5 Counter circuit of the arrester

\section{Prototype of the detector}

\subsection{Composition of the detector}

Figure 6 shows the circuit of the deterioration diagnosis device which was designed and built to prevent false operations of the existing counter due to change-over switch surge voltages, and to accurately measure the total leakage current waveform. The left side of the Fig. 6 shows the circuit to prevent false operations of the existing counter, and the right side shows the total leakage current measurement circuit. By opening the switch $\mathrm{S}$, the output of the total leakage current waveform is obtained at the terminal for measuring leakage current based on the voltage converted from the total leakage current waveform [4]. Figure 7 shows a prototype device which was installed between the arrester and the counter at a Shinkansen substation.

\subsection{Function to prevent false operation of the coun- ter [5]}

\subsubsection{Principle to prevent false operation}

Measurements revealed that the switching surge voltage accompanying operation of a change-over switch was about 40-100 kV. In this case the discharge current flowing through the arrester at that time reached a maximum of $100 \mathrm{~A}$. Frequent arrester operation caused by such highfrequency surge voltage does not generate damage which could have an impact on actual operations [2]. Therefore, as shown on the left of Fig.6, a circuit consisting of a gas tube arrester $D_{1}$ and resistor $R_{\mathrm{G}}$, was used to prevent false counter operation. Switch S opens to measure the total leakage current and is closed the remainder of the time. Discharge current from the arrester $I_{0}$ flows to resistor $R_{\mathrm{G}}$, and voltage $V_{\mathrm{R}}$ is generated between the resistor terminals. In this case, $I_{0}$ is also diverted into the leakage current measurement circuit, however, because the resistor values of $R_{\mathrm{G}}, R_{\mathrm{m} 2}$ are significantly greater than the shunt resistor $R_{\mathrm{m} 1}$, it is considered to be almost negligible. If $V_{\mathrm{R}}$ is below the firing potential $V_{\mathrm{G}}$ of the discharge tube, the discharge current bypasses the counter and flows directly to earth whereas when $V_{\mathrm{R}}>V_{\mathrm{G}}$ the gas tube arrester $D_{1}$ discharges and the current flows into the counter. For example, assuming a value of $1.5 \Omega$ for resistor $R_{\mathrm{G}}$, and a firing potential of $V_{\mathrm{G}}$ is $350 \mathrm{~V}$, if the arrester discharge current $i_{0}$ is equal to or below $230 \mathrm{~A}, D_{1}$ will not discharge, and the discharge current does not flow into the counter preventing its false operation. A varistor connected in series with the gas tube arrester $D_{1}$ is intended to prevent the backflow of charge stored in the counter's capacitor. Without this varistor, even when the discharge current from the arrestor is very large, there is a possibility that the counter will fail to operate. 


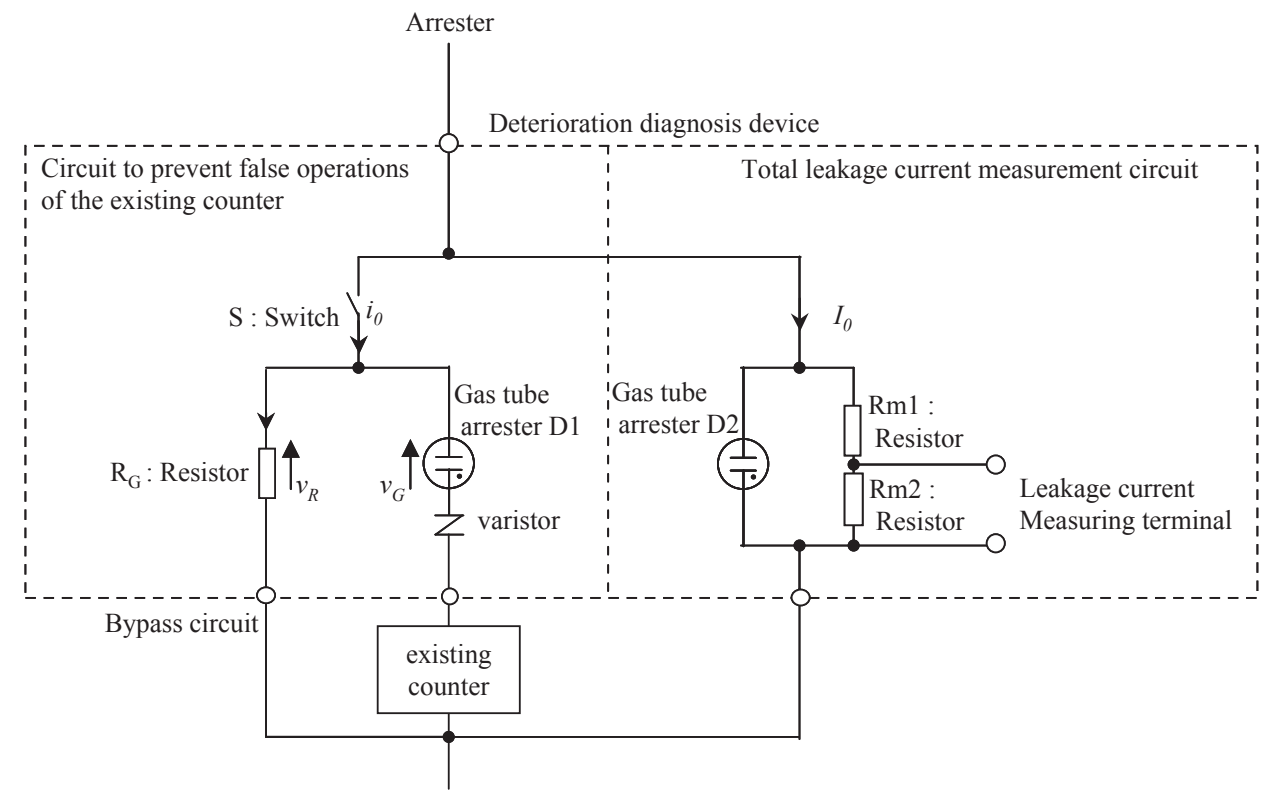

Fig. 6 Configuration of the arrester current detector

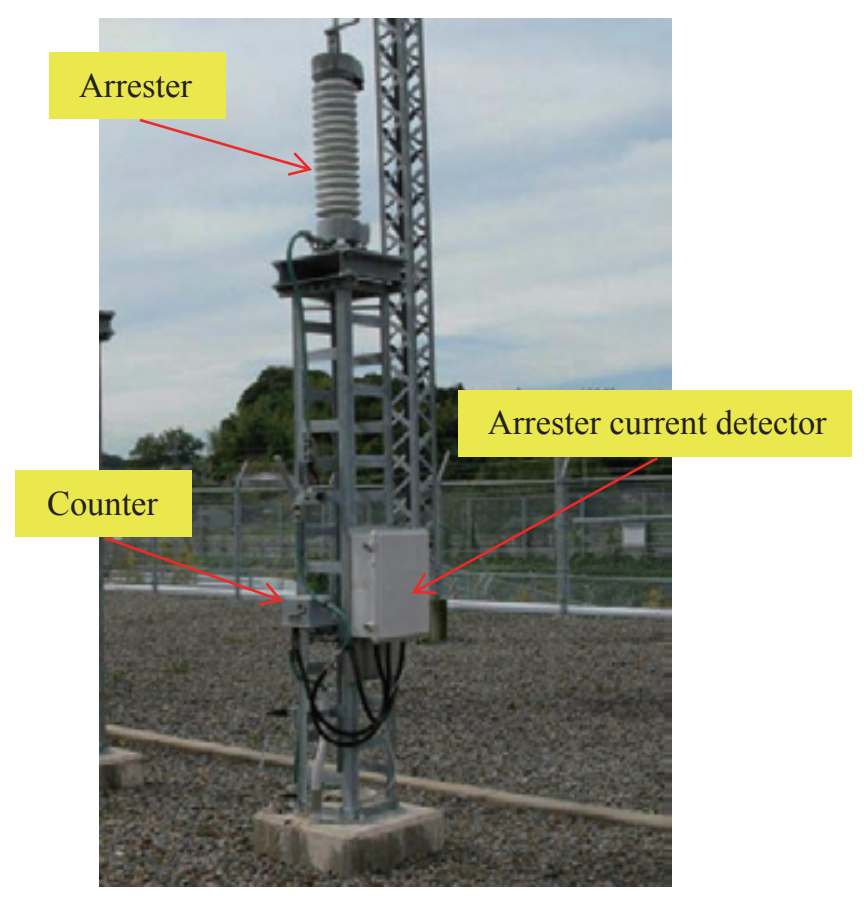

Fig. 7 Configuration of the arrester current detector

\subsubsection{Discharge current of Arrester from lightning surge}

Half the current value (average value) of a direct lightning hit is about $25 \mathrm{kA}$. However, if there is a direct lightning hit to a distant contact line, the surge voltage reaching the substation is limited by the insulator flashover voltage. When a double insulation method is employed to protect the contact lines consisting of protective wires for the insulator, the lightning impulse flashover voltage of an rod porcelain insulator at the positive electrode is 381
$\mathrm{kV}$ and (measured value) $472 \mathrm{kV}$ at the negative electrode. However if a surge voltage of $400 \mathrm{kV}$ reaches the substation, the surge impedance of the contact line will be 200 $\Omega$ and discharge current flowing into the arrester will be around 2,000 A (400 $\mathrm{kV}_{\text {0-P }} / 200 \Omega$ ). Consequently if the counter operates with a current flows into the arrester of about 2,000 A, it is possible to record electric discharges from lightning surges.

\subsubsection{Effect of the circuit for preventing false opera- tion of the counter}

A prototype device for detecting arrester current was introduced into the ground circuit of a Shinkansen substation whereby it was possible to confirm its effective operation during change-over switching. Figure 8 shows a typical resulting waveform. Figure 8 also clearly shows that the surge voltage rises sharply from the point situated between 20 and $27 \mu \mathrm{s}$ on the time axis. A Surge current of about 100 A flows through the varistor by-pass circuit at this point, and since there is no spill over of current to the counter, it remains inactive.

The above clearly demonstrates that the circuit designed to prevent false operation of the counter in the arrester current detection device functions effectively.

Figure 9 shows the waveform produced when a current of $650 \mathrm{~A}$ is passed through the arrester using the lightning impulse generator. In this case the gas tube arrester $D_{1}$ produces a discharge and the counter is activated by a current of $85 \mathrm{~A}$. This demonstrates that the counter would definitely operate under the expected lightning discharge current of 2,000 A. The latter therefore confirms that introducing the prototype of the arrester current detector into the ground circuit of the arrester would prevent activation of the counter for currents of around $100 \mathrm{~A}$ produced during changer-over switching, but would react to surge currents. 


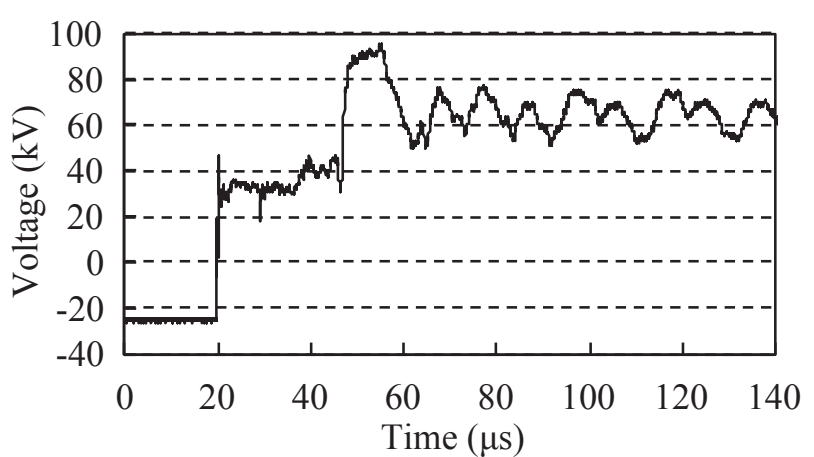

(a) Voltage of arrester

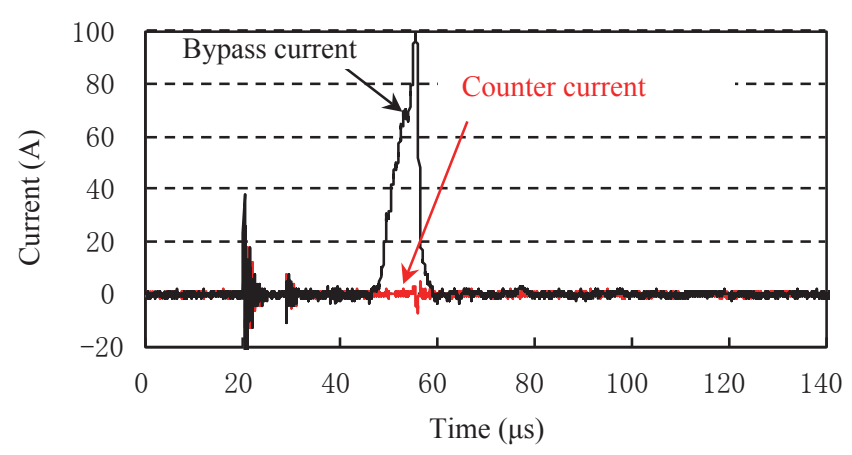

(b) Current of arrester

Fig. 8 Current in the circuit for preventing false operation of the counter

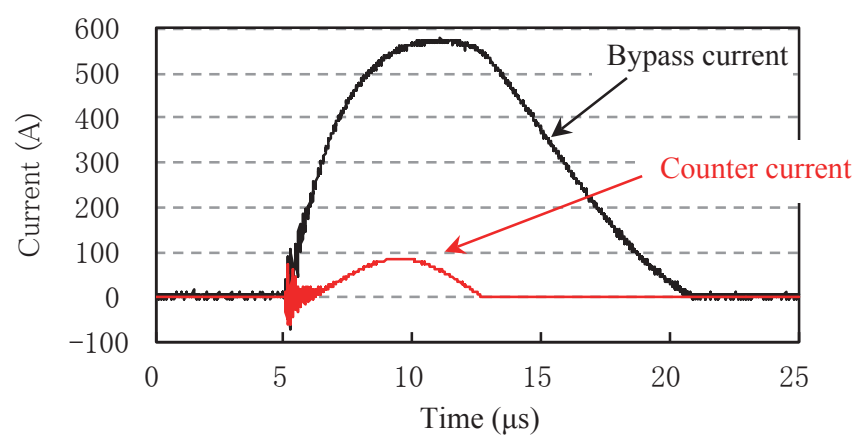

Fig. 9 Waveform produced during counter operation (during lightning impulse tests)

\subsection{Total leakage current waveform measurement function}

It is possible to measure the leakage current from the arrester from the arrester ground circuit. However, as mentioned above, the current measured by the arrester ground circuit is the total leakage current, i.e. the sum of $I_{\mathrm{R}}$ and the $I_{\mathrm{C}}$ which is dominant. Therefore, in order to be able to detect an increase in $I_{\mathrm{R}}$ which is only a fraction of the total leakage current, but which is required to diagnose any damage to any of the elements, it is necessary to obtain very precise measurements. When the $\mathrm{S}$ switch opens, the arrester current only flows through the noninductive resistors $(5 \mathrm{k} \Omega) R_{\mathrm{m} 2}$ and $R_{\mathrm{m} 1}(100 \mathrm{k} \Omega)$, in the total leakage current measurement circuit. The waveform of the

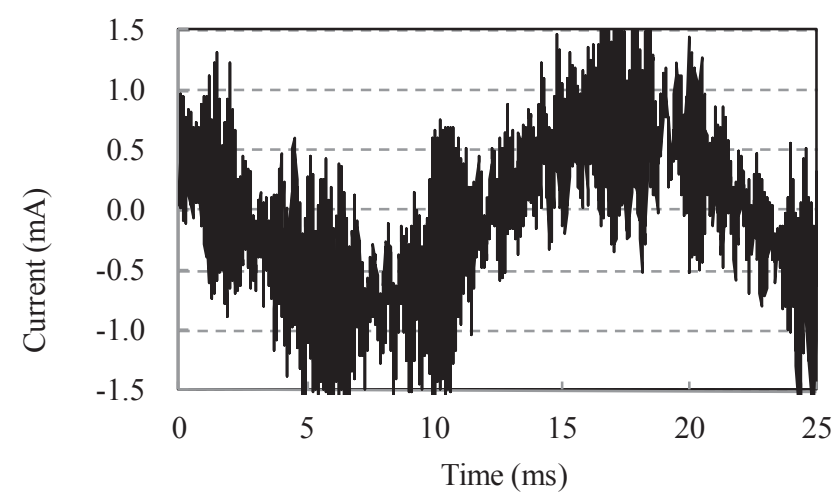

(a) Waveform measured by the clamp-type ammeter

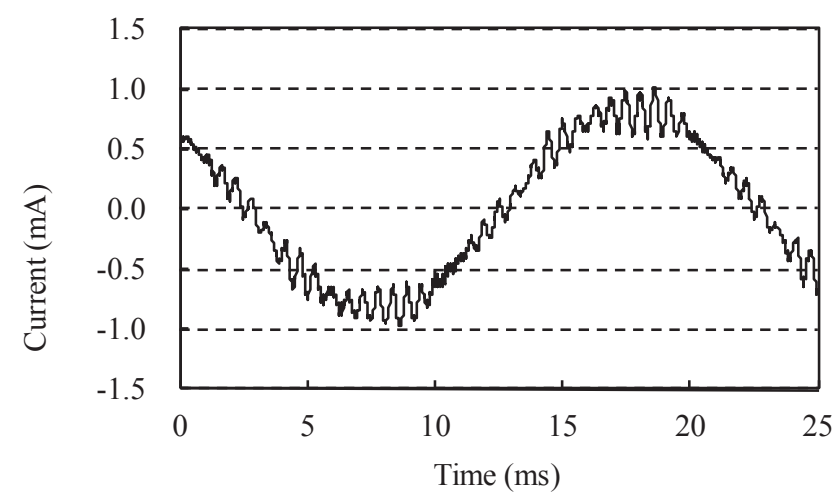

(b) Waveform measured by the arrester current detector

Fig. 10 Comparison of measured waveforms (synchronous measurement) Clamp-type meter and arrester current detector

leakage current can be detected by measuring the voltage waveform between the terminals of resistor $R_{\mathrm{m} 2}$. During the measurement process however, there is a possibility of an extremely large surge voltage being generated due to the surge current flowing into the total leakage current measurement circuit from an arrester discharge resulting from the surge caused by operation of the change-over switch.

In order to offer protection against surge voltage, a gas tube arrester $D_{2}$ with a direct discharge trigger voltage of $550 \mathrm{~V}$ is connected in parallel to the resistor. This suppresses the applied voltage. In addition $R_{\mathrm{m} 1}(100 \mathrm{k} \Omega)$ is connected in series to $R_{\mathrm{m} 2}(5 \mathrm{k} \Omega)$ for measuring the leakage current. By adopting this approach, the surge voltage produced in $R_{\mathrm{m} 2}$ is reduced to $1 / 20$ of its value, thanks to the control by gas tube arrester $D_{2}$. Following on, since the arrester resistance is over $1,000 \mathrm{M} \Omega$, a resistance of 100 $\mathrm{k} \Omega$ only represents $0.01 \%$ of this value. Therefore, introducing a resistance of $100 \mathrm{k} \Omega$ to the ground circuit would not affect the total leakage current. Figure 10 compares the total leakage current waveforms obtained with a generic clamp-style ammeter and with the arrester current detector (non-inductive type resistance). Results revealed that the waveform obtained with the non-inductive type resistance is comparative free from noise interference, and is therefore more accurate. 


\section{Detecting the current flowing through the resis- tor}

\subsection{Principle of detection}

This chapter describes in detail how current flowing through the resistor is detected from the arrester leakage current and arrester voltage waveforms. The underlying principle is shown in Fig.11.

This figure gives instantaneous voltage and current values for all the symbols. Equation (1) shows the capacitive current $i_{\mathrm{c}}$ is derived from the capacitance $C$ of the arrester and the deviation of line voltage.

$$
i_{C}=C \frac{d v}{d t}
$$

Since the total leakage current $I_{0}$ is the sum of $I_{\mathrm{R}}$ and $I_{\mathrm{C}}, I_{\mathrm{R}}$ is $(2)$.

$$
i_{R}=i_{O}-i_{C}
$$

Equation (3) is obtained by substituting (2) with (1).

$$
i_{R}=i_{O}-C \frac{d v}{d t}
$$

Thus, after obtaining the waveforms for $I_{0}$ and the arrester voltage $V, I_{\mathrm{R}}$ can be found by differentiation of the voltage waveform by applying (3). Subsequently, the effective value of the resistance current $I_{\mathrm{R}}$ can be determined by (4). Where $C$ is unclear, its value can be adjusted until $I_{\mathrm{R} \text {-rms }}$ reaches a minimum using (4), and this minimum value is the resistance current $I_{\mathrm{R} \text {-rms. }}$.

$$
I_{R-r m s}=\sqrt{\frac{1}{T} \int_{0}^{T}\left(i_{O}-C \frac{d v}{d t}\right)^{2} d t}
$$

$\mathrm{T}$ where is the cycle of the AC current $(50 \mathrm{~Hz} / 60 \mathrm{~Hz})$

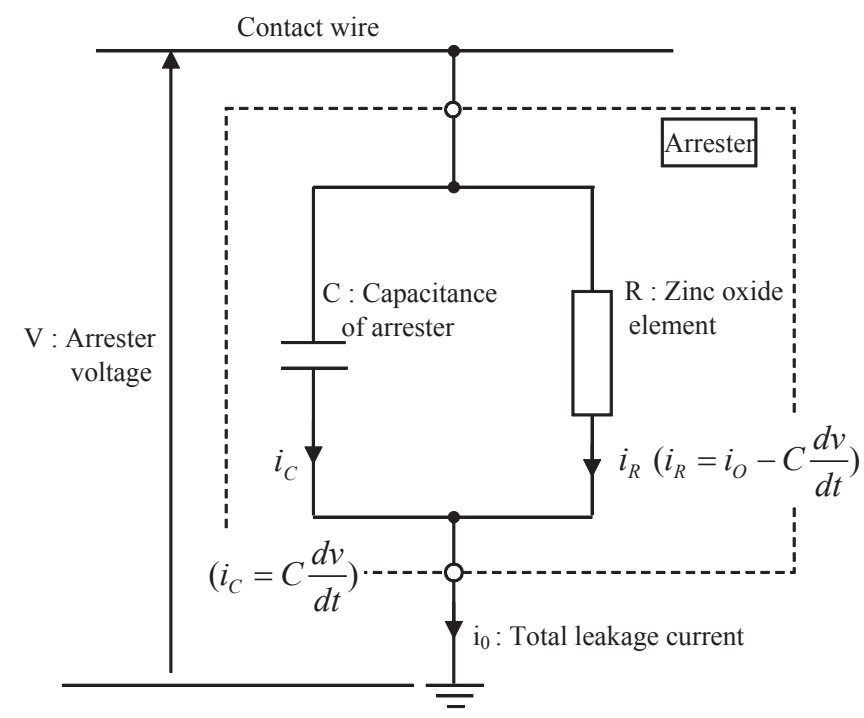

Fig. 11 The principle of detecting current flowing through a resistor by voltage waveform differentiation.

\subsection{How to use an approximate expression of the waveform}

The voltage waveform can be differentiated using either an analog or digital method. In this paper, $I_{\mathrm{R}}$ was detected by arithmetic processing of the waveform data ob- tained from a generic measuring instrument. This method makes it is necessary to obtain the differential waveform of the voltage waveform. However using differentiation of measured data amplifies instantaneous changes making it difficult to obtain the appropriate waveform, Therefore, the measured voltage waveform is approximated using a function equation, after which mathematical differentiation is used on the approximation formula. Equation (5) is the approximation equation, and (6) is the expression used to differentiate (5).

$v(t)=a_{0}+a_{1} \sin \left(\omega t+\varphi_{1}\right)+a_{2} \sin \left(2 \omega t+\varphi_{2}\right)+\cdots+a_{n} \sin \left(n \omega t+\varphi_{n}\right)$

$\frac{d v(t)}{d t}=\omega a_{1} \cos \left(\omega t+\varphi_{1}\right)+2 \omega a_{2} \cos \left(2 \omega t+\varphi_{2}\right)+\cdots+n \omega a_{n} \cos \left(n \omega t+\varphi_{n}\right)$

Appropriate initial values were attributed for amplitude $a_{\mathrm{n}}$ and phase $\varphi_{\mathrm{n}}$ in (5) in order to obtain the approximation equation for the voltage waveform and measured data was used alongside the least squares method which is the smallest square error. If the values obtained for the amplitude value and phase value are applied in (6), it is possible to find the differentiated waveform of the voltage waveform. Subsequently, the resistance current waveform $I_{\mathrm{R}-\mathrm{rms}}$ can be obtained by applying the previously obtained differentiated voltage waveform to (3).

\subsection{Results of detection}

Figure 12 illustrates the resistance current waveforms obtained using (3) and the leakage current measured by the prototype lightning arrester current detection device. Figure 12(a) shows the results after processing the output from the existing substation voltage transformer and the leakage current of the arrester on the feeder line in the same substation. Figure 12(b) shows the results in detecting the resistance current from the leakage current waveform measured on the prototype arrester current device, after generating the replica of a damaging voltage surge in the train arrester using a test-use transformer.

Figure 12(a) shows that the leakage current waveform includes many harmonics, nonetheless, the peak extracted wave value of $I_{\mathrm{R}}$ is $0.06 \mathrm{~mA}$, demonstrating normal function of the arrester. By contrast Fig.12(b) clearly shows an increase in $I_{\mathrm{R}}$ indicating that the excess current has damaged the arrester. These results demonstrate therefore that the present method can be used to accurately detect the resistance current.

\section{Conclusions}

(1) The measured surge voltage caused by changeover switching in Shinkansen substations, was about $90 \mathrm{kV}$ or more. This surge voltage produces a current of about 100 A flowing through the arresters. However, such small currents do not affect the lifetime of the arrester. Considering the abovementioned fact, a prototype measuring device was developed including a discharging tube, which prevents false operation of the counter, and a noninductive resistor, which enables precise measurement of the current.

(2) The total leakage current of the arrester is the sum of the resistance current $I_{\mathrm{R}}$ and the capacitance 


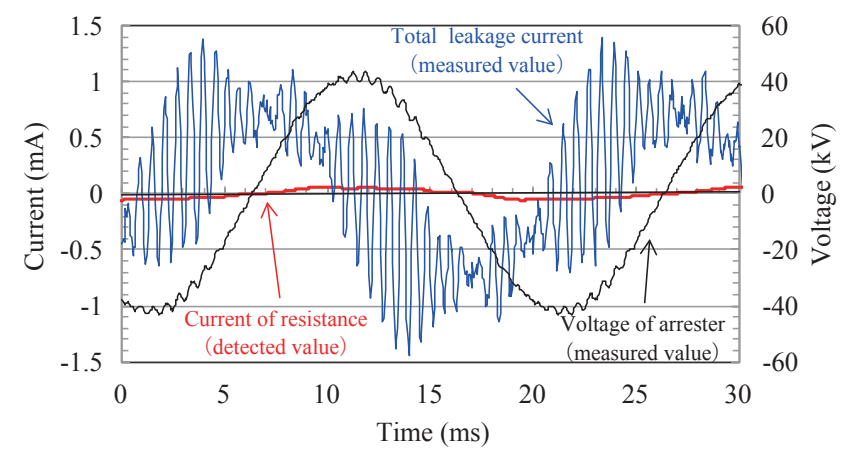

(a) A normal waveform (Actual measurement, Shinkansen substation arrester)

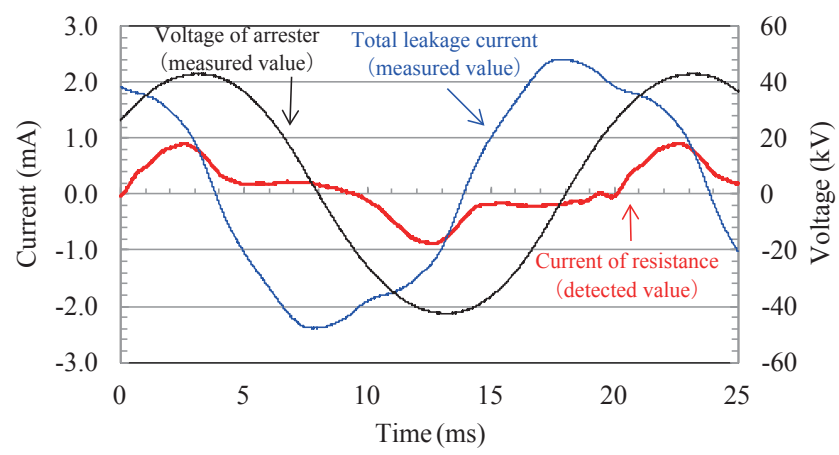

(b) Waveform to increase the current through the resistor

Fig. 12 Current waveform detecting resistance

current $I_{\mathrm{C}}$. The phase of the total leakage current was approximately 90 degrees ahead of the phase of the arrester voltage waveform. $I_{\mathrm{C}}$ is dominant in the total leakage current.

(3) The following method was found to be suitable for obtaining the resistive current, by using a function to approximate the voltage waveform and obtaining the capacitance current from mathematical differentiation of the function, and subsequently subtracting the capacitance resistance from the total leakage resistance.

(4) Based on the above, a measuring device was developed which can accurately measure the resistance current. It was demonstrated that introduction of this device can prevent false operation of the counter, and can detect the capacitance current required for detecting damage to the arrester. It is expected that data collected from a prototype device experimentally installed in a Shinkansen substation, will facilitate management of arrester damage.

\section{References}

[1] Takizawa, K., Ajiki, K., Hino, M., Itoda, K., "Study of Management Method for Arrester Deterioration Using for Feeder Line of Shinkansen," The 2009 annual meeting record I.E.E.J, No.5-603, 2009 (in Japanese).

[2] Horie, S., Takagi, K., Tone, H., Ogawa, T., Hayashiya, H., Morino, S., "Development of Counter for arrester operation distinct in discharging current level," The Paper of Technical Meeting, I.E.E.J, TER-08-34, pp.3134, 2008 (in Japanese).

[3] Ajiki, K., Uzuka, T., Inami, K., Uchinuma, K., “ Measurements of surge voltage change-over switch for airless Shinkansen," Proc. of JIASC2004, vol.3, pp.343344, 2004 (in Japanese).

[4] Takizawa, K., Ajiki, K., Yoshii, T., "Management Method for Arrester Deterioration Using Arrester Leakage Current for Feeder Line of Shinkansen," Proc. of JIASC2009, vol.3, pp.271-276, 2009 (in Japanese).

[5] Ajiki, K., Morimoto, H., Akagi, M., Hino, M., Anno, D., Uchinuma, K., "Test Result of Measuring Device for Arrester Leakage Current in shinkansen Feeding System," The 2010 annual meeting record I.E.E.J, No.5503, 2010 (in Japanese). 